\title{
Endometriosis-A Multifaceted Problem of a Modern Woman
}

\author{
Alicja Mińko 1,*(D), Agnieszka Turoń-Skrzypińska ${ }^{1}$, Aleksandra Rył ${ }^{1}$ (D) Patrycja Bargiel ${ }^{2}$, Zuzanna Hilicka ${ }^{2}$, \\ Kaja Michalczyk ${ }^{3} \mathbb{D}$, Paulina Łukowska ${ }^{3}$, Iwona Rotter ${ }^{1} \mathbb{D}$ and Aneta Cymbaluk-Płoska ${ }^{3} \mathbb{D}$
}

1 Department of Medical Rehabilitation and Clinical Rehabilitation, Pomeranian Medical University, ul. Żołnierska 54b, 71-210 Szczecin, Poland; agi.skrzypinska@gmail.com (A.T.-S.); ryl.ola@gmail.com (A.R.); iwrot@wp.pl (I.R.)

2 Student Science Club “KINEZIS”, Department of Medical Rehabilitation and Clinical Physiotherapy, Pomeranian Medical University, 71-210 Szczecin, Poland; bargiel2727@o2.pl (P.B.); hilickaz@gmail.com (Z.H.)

3 Department of Gynecological Surgery and Gynecological Oncology of Adults and Adolescents, Pomeranian Medical University, al. Powstańców Wielkopolskich 72, 70-111 Szczecin, Poland; kajamichalczyk95@gmail.com (K.M.); lukowska.paulina95@gmail.com (P.Ł.); anetac@data.pl (A.C.-P.)

* Correspondence: alicja.minko287@gmail.com

\section{check for}

updates

Citation: Mińko, A.;

Turoń-Skrzypińska, A.; Rył, A.;

Bargiel, P.; Hilicka, Z.; Michalczyk, K.;

Łukowska, P.; Rotter, I.;

Cymbaluk-Płoska, A.

Endometriosis-A Multifaceted

Problem of a Modern Woman. Int. J.

Environ. Res. Public Health 2021, 18,

8177. https://doi.org/10.3390/

ijerph18158177

Academic Editor: Paul B. Tchounwou

Received: 4 July 2021

Accepted: 30 July 2021

Published: 2 August 2021

Publisher's Note: MDPI stays neutral with regard to jurisdictional claims in published maps and institutional affiliations.

Copyright: (c) 2021 by the authors. Licensee MDPI, Basel, Switzerland. This article is an open access article distributed under the terms and conditions of the Creative Commons Attribution (CC BY) license (https:/ / creativecommons.org/licenses/by/ $4.0 /)$.

\begin{abstract}
Endometriosis is a chronic disease of unclear aetiology that affects millions of women around the world. It causes chronic pain, dysmenorrhea, and infertility, which significantly reduces the quality of daily life. The aim of the following study was a multivariate analysis of the functioning of women diagnosed with endometriosis, and the identification of the relationship between the level of physical activity and sexual functioning, ability to cope with stress, and the degree of anxiety and mood disorders. The prospective survey was conducted of 957 women. The research was carried out using standardised IPAQ, FSFI, HADS, and Mini-Cope questionnaires. The study showed that patients with endometriosis exhibit a higher level of depression and anxiety disorders $(p=0.01)$ and a lower level of sexual functions $(p<0.001)$. The influence of physical activity on the functioning of patients with endometriosis was demonstrated. Depending on the clinical stage of endometriosis, the influence of physical activity on individual aspects of life differed. Physical activity was shown, inter alia, to reduce anxiety $(p=0.015)$, and influence stress-coping strategies. Endometriosis affects the mental and physical health of women. Physical activity can reduce the severity of endometriosis symptoms and improve the daily functioning of patients.
\end{abstract}

Keywords: endometriosis; physical activity; depression; anxiety; sexual function; coping with stress

\section{Introduction}

Endometriosis is a chronic, progressive disease of unclear aetiology. It is characterised by the growth of endometrial tissue outside the uterine cavity and chronic inflammation of the affected anatomical structures-most often the pelvic organs. It is one of the most common gynaecological diseases [1,2]. It is estimated that the incidence of endometriosis ranges from 2 to $17 \%$ of women of reproductive age, which represents over 170 million women globally [3,4]. In Poland, the disease affects about 1 million people [5]. The rate of diagnosed cases is much higher among women with infertility (25-50\%), dysmenorrhea (40-60\%), and pelvic pain (71-87\%) [6,7]. The pathomechanism of endometriosis is based on several theories. The main one is the theory of retrograde menstruation, which is the movement of endometrial tissues through the fallopian tubes during menstruation. Other theories of the development of endometriosis are related to genetic predisposition, environmental factors, immune disorders, and lifestyle [8,9].

With regard to recent literature, the non-modifiable risk factors for endometriosis include age, family history, education level, and the age of the first menstruation (menarche). No association between lifestyle factors, such as alcohol/caffeine consumption or smoking, and the incidence of endometriosis has been established. A weak correlation between the lack of physical activity and an increased risk of endometriosis has been 
demonstrated $[10,11]$. The most common symptoms of the disease include dysmenorrhea (60-80\%), chronic pelvic pain (30-50\%), infertility (30-40\%), and dyspareunia (25-40\%) [12]. In accordance with the classification introduced by the American Society for Reproductive Medicine (ASRM), there are four stages of endometriosis. The relationship between the staging of endometriosis and the pain severity remains unclear $[13,14]$. In accordance with the recent literature, there is evidence that the age of women with advanced-stage endometriosis was slightly higher at diagnosis. The highest incidence was recorded among women aged 25-29, whereas the lowest was among women aged over 44 [15,16]. Moreover, the symptoms were found to alleviate in postmenopausal women due to reduced oestrogen production [17]. Endometriosis is difficult to diagnose due to the gaps in knowledge among healthcare professionals about the condition. This applies especially to uncertainty regarding the pathogenesis, heterogeneity of the course of the disorder, or its symptoms, which are often confused with other mental or physical disorders. Due to the aforementioned factors, the diagnosis of endometriosis is often overlooked, which is a serious social problem $[12,18,19]$. Treatment based on pharmacological methods relieves the symptoms of the disease but may involve the occurrence of side effects and a recurrence of symptoms after discontinuation of use. Laparoscopy, the purpose of which is ablation or excision of lesions, is considered the gold standard in the diagnosis and treatment of endometriosis [9]. The pharmacological and surgical treatment significantly affects the quality of life of patients with endometriosis; however, there are multiple factors that can significantly affect the functioning of women. Women suffering from endometriosis can experience a variety of non-clinical symptoms. Endometriosis has been found to have a negative impact on physical, mental, and social well-being $[20,21]$. The pain associated with endometriosis is the key factor that reduces the quality of life because it can lead to reduced sleep quality, more perceived stress, lower levels of physical activity, and mental disorders, such as anxiety and depression. Moreover, it negatively influences sexual activity, which has further consequences for intimate and social relations [22,23]. The adverse effects experienced by patients with endometriosis significantly contribute to problems with productivity, relationship difficulties, and social dissatisfaction. Endometriosis is therefore a pathology that can significantly affect the quality of women's life in multiple dimensions $[1,24,25]$. Modern treatment of endometriosis should be personalised using a patient-centred, interdisciplinary approach. Pharmacological treatment may not be sufficient. Complementary to the therapy, a psychological, dietary, urological, and physiotherapy intervention is recommended [26-28].

The aim of this study was to determine the impact of endometriosis on women's functioning, and to identify the mutual relationship between the level of physical activity, sexual functioning, and the degree of anxiety and depression disorders among women with endometriosis. Moreover, the study also included the analysis of the relationship between the level of physical activity and sexual functioning, coping skills, and the degree of anxiety and mood disorders, taking into account the clinical advancement of endometriosis.

\section{Materials and Methods}

\subsection{Survey Sample}

The prospective study was conducted from March 2019 to April 2021 and included 957 women. The respondents were divided into two groups: study group (B) and control group (C). The group B consisted of 484 people, and the group C of 473 . The minimum sample size was 384 . The inclusion criteria for the study in both groups were the age from 18 to 55 years and fully completed questionnaires (FSFI, HADS, IPAQ, and MiniCope). Only women with clinically diagnosed endometriosis were included in group B. Group C was composed of women without endometriosis. It was used as a reference for the analysis of the results in group B. The literature data [29-31] shows that there are multiple factors, including the stress level, level of physical activity, depression and anxiety disorders, and sexual functioning, which differ in terms of groups of women with and without endometriosis. 
Minors and persons over 55 were excluded from the study. Women with concomitant diseases, such as rheumatoid diseases, hypertension, atherosclerosis, diabetes, infertility, epilepsy, and gynaecological problems, treatment of which could have an impact on the assessment of functioning and quality of life, could not take part in the study. Persons who did not reply to all of the questions included in the questionnaires were also excluded. Only complete questionnaires were used in the analysis. All questionable data were discarded. Ultimately, taking into account all of the inclusion and exclusion criteria, 439 women qualified for group B, and 421 for group C (Figure 1). Group B was recruited through internet forums associating women with endometriosis. Group $C$ was gathered via publicly available social networks. The study collected demographic data and data on risk factors and the course of the disease, such as: age, education, the occurrence of addictive behaviours (smoking and drinking alcohol), the course of the menstrual cycle, multiple pregnancies, and the occurrence of miscarriage. Women diagnosed with endometriosis were additionally assessed in terms of the location of the foci and the presence of accompanying symptoms. The above variables were treated only as information concerning the group characteristics and they were not taken into account in further analyses.

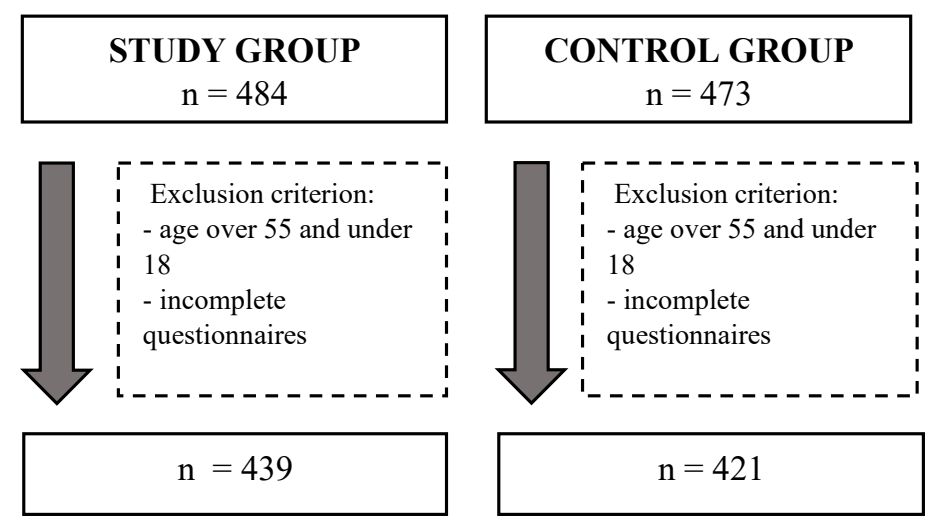

Figure 1. Flowchart.

\subsection{Questionnaires}

The survey was conducted using standardised questionnaires: International Physical Activity Questionnaire (IPAQ), Female Sexual Function Index (FSFI), Mini-Cope, and Hospital Anxiety Depression Scale (HADS) translated into Polish.

The level of physical activity was assessed using the IPAQ questionnaire, which expresses physical activity in MET-minutes/week units. On the basis of the obtained results, the study participants could be classified according to their level of physical activity into one of three categories: high (over 1500 or 3000 MET-minutes / week), sufficient (600-1500 or 600-3000), or insufficient (below 600 MET-minutes/week) [32,33]. The IPAQ questionnaire demonstrated acceptable accuracy and reliability in the assessment of physical activity among adults. The criteria validity had a rho median that approximately equalled 0.30 , which was comparable with most other self-reported validation studies [34,35].

Female sexual function was assessed using the FSFI questionnaire, the purpose of which was to determine significant clinical sexual dysfunctions. The questionnaire consists of 19 questions, divided into 6 domains, assessing such factors as: desire, arousal, lubrication, orgasm, sexual satisfaction, and pain related to sexuality [18]. The overall FSFI score ranges from 0 to 36 points. The higher the score, the better the sexual function. Women with a score of 26 or less were classified as having sexual dysfunction [36,37].

The validation studies of the FSFI scale showed its reliability and validity. Overall test-retest reliability coefficients were high for each of the individual domains $(r=0.79$ to 0.86 ). A high degree of internal consistency was demonstrated by the Cronbach alpha value (0.963). The analysis of intraclass correlations showed a high degree of correlation between total and subscale results $(r=0.848-0.943, p<0.001)$ [38]. 
The HADS questionnaire was used to determine the level of anxiety and depression. The questionnaire consists of two domains (anxiety and depression), each assessed in the range of 0 to 21 points. Women with a score of $\leq 7$ did not show symptoms of depression or anxiety. A greater number of points indicated a higher level of depressive and anxiety behaviours, defined as mild (8-10 points), moderate (11-14 points), and severe (15-21 points) $[18,39]$. The validation studies of the HADS scale showed its reliability and validity. Spearman's rank co-relation between the test items and the overall score of a given subscale was statistically significant $(p<0.01)$ and ranged from 0.41 to 0.76 . The mean sensitivity and specificity were $\geq 0.80$, similar to that of other self-assessment tools. Similar alpha coefficients were observed for the translated versions [40].

Strategies for coping with stress were assessed using the Mini-COPE questionnaire, which consists of 28 questions. They form 14 subgroups, including various strategies of coping with difficult situations. These include: active coping, planning, positive reframing and development, acceptance, sense of humour, turning to religion, seeking emotional support, seeking instrumental support, self-distraction, denial, venting, use of alcohol and psychoactive substances, discontinuation of actions, and self-blame. The results were analysed separately for each strategy, and their range was from 0 to 3 points. The higher the result, the more often a given strategy was adopted. The internal compliance of the Polish version of Mini-COPE was established based on a study of 200 patients aged 2560 years. The half-time reliability was 0.86 (Guttman's index 0.87 ). The consistency was satisfactory for most scales $[41,42]$. The respondents completed an original questionnaire, which included sociodemographic, health, and lifestyle questions.

The study was conducted in accordance with the standards of the Helsinki Declaration. It was approved by the Bioethics Committee of the Pomeranian Medical University (decision no KB-0012/47/04/2021/Z).

\subsection{Statistical Analysis}

The statistical analysis was performed with Statistica version 13.1. The study group was characterised taking into account the number of patients, their percentage share, mean, minimum and maximum, and standard deviation. The normality of the distribution was tested with the Shapiro-Wilk test. The relationships between the groups were analysed with the Student's $t$-test and the Mann-Whitney U test. Correlation analysis was performed with the Spearman's rho test. Nominal variables were tested with the chi-squared test. Results where $p<0.05$ were considered statistically significant.

\section{Results}

\subsection{Group Characteristics}

A total of 860 patients were included in the study. The patients were characterised in terms of age, education, and the presence of habitual behaviours (smoking and drinking alcohol). The analysed factor was the course of the menstrual cycle, multiple pregnancies, and the occurrence of miscarriage. The mean $( \pm \mathrm{SD})$ age in the study group was $33.1 \pm 6.0$ years, and in the control group was $32.6 \pm 7.0$ years. The characteristics of women with endometriosis compared to the healthy population are presented in Table 1.

The study group was characterised in terms of the clinical stage of the disease, the location of endometriosis lesions, the presence of accompanying symptoms, the method of diagnosis, and the areas of possible help, taking into account the age groups of 18-25, $25-35,35-45$, and over 45.

The greatest number of women (33.3\%) suffered from stage 4 endometriosis. Slightly fewer $(30.5 \%)$ persons were in stage 1 (Table 2$)$. 
Table 1. Comparison of the demographic data of the test group and the control group.

\begin{tabular}{|c|c|c|c|c|c|c|}
\hline \multirow{2}{*}{\multicolumn{2}{|c|}{ Variable }} & \multicolumn{2}{|c|}{ Group B } & \multicolumn{2}{|c|}{ Group C } & \multirow{2}{*}{$p$-Value } \\
\hline & & $\mathbf{M}$ & Min-Max & $\mathbf{M}$ & Min-Max & \\
\hline \multirow{2}{*}{\multicolumn{2}{|c|}{ Age }} & 33.1 & $19.0-55.0$ & 32.6 & $18.0-50.0$ & 0.235 \\
\hline & & $\mathbf{N}$ & $\%$ & $\mathbf{N}$ & $\%$ & $p$-Value \\
\hline \multirow{5}{*}{ Education } & Primary & 5 & $1.13 \%$ & 3 & $0.71 \%$ & \multirow{5}{*}{$<0.001$ * } \\
\hline & junior high school & 2 & $0.45 \%$ & 5 & $1.18 \%$ & \\
\hline & vocational & 4 & $0.91 \%$ & 16 & $3.80 \%$ & \\
\hline & secondary & 106 & $24.14 \%$ & 163 & $38.71 \%$ & \\
\hline & Higher & 322 & $73.34 \%$ & 234 & $55.58 \%$ & \\
\hline \multirow{5}{*}{ Menstrual cycle } & $\begin{array}{l}\text { stopped by } \\
\text { medication }\end{array}$ & 123 & $14.30 \%$ & 28 & $3.26 \%$ & \multirow{5}{*}{$<0.001 *$} \\
\hline & Regular & 138 & $16.05 \%$ & 172 & $20.00 \%$ & \\
\hline & quite regular & 119 & $13.84 \%$ & 173 & $20.12 \%$ & \\
\hline & irregular & 53 & $6.16 \%$ & 47 & $5.47 \%$ & \\
\hline & $\begin{array}{c}\text { I am bleeding all the } \\
\text { time }\end{array}$ & 6 & $0.70 \%$ & 1 & $0.12 \%$ & \\
\hline \multirow{2}{*}{ Occurrence of miscarriage } & Yes & 70 & $13.49 \%$ & 65 & $12.52 \%$ & \multirow[b]{2}{*}{0.249} \\
\hline & No & 177 & $34.10 \%$ & 207 & $39.88 \%$ & \\
\hline \multirow{3}{*}{ Multiple pregnancies } & one child & 172 & $43.11 \%$ & 203 & $50.88 \%$ & \multirow{3}{*}{0.746} \\
\hline & Twins & 9 & $2.26 \%$ & 14 & $3.51 \%$ & \\
\hline & triplets or more & 0 & $0.00 \%$ & 1 & $0.25 \%$ & \\
\hline \multirow{2}{*}{ Smoking cigarettes } & Yes & 62 & $14.12 \%$ & 106 & $25.17 \%$ & \multirow{2}{*}{$<0.001$ * } \\
\hline & No & 377 & $85.87 \%$ & 315 & $74.82 \%$ & \\
\hline \multirow{5}{*}{ Drinking alcohol } & does not drink & 92 & $10.71 \%$ & 71 & $8.27 \%$ & \multirow{5}{*}{$0.017^{*}$} \\
\hline & occasionally & 233 & $27.12 \%$ & 210 & $24.45 \%$ & \\
\hline & once a week & 76 & $8.85 \%$ & 75 & $8.73 \%$ & \\
\hline & once a month & 35 & $4.07 \%$ & 58 & $6.75 \%$ & \\
\hline & every day & 2 & $0.23 \%$ & 7 & $0.81 \%$ & \\
\hline
\end{tabular}

Group B—study group; Group C—control group; $p$-value—statistical significance; * —statistically significant value; $\mathrm{N} —$ number.

Table 2. The division of the study group according to endometriosis staging with regard to age groups.

\begin{tabular}{|c|c|c|c|c|c|}
\hline Variable (Age) & Stage I & Stage II & Stage III & Stage IV & $p$-Value \\
\hline 18-25 years old & 20 & 10 & 6 & 10 & \multirow{5}{*}{0.046 * } \\
\hline 25-35 years old & 71 & 42 & 50 & 73 & \\
\hline $35-45$ years old & 40 & 23 & 25 & 62 & \\
\hline Above 45 years old & 3 & 2 & 1 & 1 & \\
\hline Overall & $134(30.5 \%)$ & $77(17.5 \%)$ & $82(18.7 \%)$ & $146(33.3 \%)$ & \\
\hline
\end{tabular}

$p$-value-statistical significance; ${ }^{*}$ - statistically significant value

In the 18-25 age group, the most common endometriosis foci were localised in the ovaries $(67.39 \%)$, the peritoneum $(36.96 \%)$, and the fallopian tubes $(21.74 \%)$. The analysis of the results in the 25-35 age group was as follows: the endometriosis lesions were present in the ovaries $(72.34 \%)$, fallopian tubes (31.91\%), and peritoneum (30.93\%). In the groups of $35-45$ years and over 45 years of age, respectively, the data were as follows: ovaries $(74 \%$ and $57.14 \%)$, peritoneum $(37.33 \%$ and $14.29 \%$ ) and fallopian tubes $(31.33 \%$ and $14.29 \%)$. The most persistent complaint reported by the respondents in all age groups was pain during menstruation (group 18-25 years old: $80.43 \%$, group $25-35$ years old: $88.14 \%$, group $35-45$ years old: $84 \%$, group over 45 years old: $57.14 \%$ ) and in the pelvic region (age group 18-25: 73.91\%, age group 25-35: 66.10\%, age group 35-45: 63.09\%, age group over 45: $57.14 \%$ ). The method used to diagnose the presence of endometriosis in most cases 
was laparoscopic surgery (age group 18-25: 52.17\%, age group 25-35: 59.32\%, age group 35-45: $59.33 \%$, age group over 45: 57.14\%). One of the least used diagnostic methods was ultrasound examination (group 18-25 years old: 43.48\%, group 25-35 years old: $34.32 \%$, group 35-45 years old: $28 \%$, group over 45 years old: $42.86 \%$ ). Most respondents expressed their willingness to obtain assistance in the search for the optimal method of treatment $(66.67 \%)$ and therapy financing $(63.89 \%)$. The interest for aid and assistance in different areas of life varied across different age groups. The respondents aged 18-25 mainly expressed the will to receive help in treatment financing $(67.39 \%)$ and choice of optimal treatment method (60.87\%), in addition to psychological (50\%) and dietary (50\%) support. In the 25-35 age group, most women required information on the optimal method of treatment $(66.53 \%)$, treatment financing $(64.83 \%)$, and relapse prevention $(56.36 \%)$. In the 35-45 age group, the greatest number of women wanted to receive help in the choice of optimal treatment method $(66.67 \%)$, relapse prevention $(62 \%)$, and treatment financing $(59.33 \%)$. The data in the age group over 45 years old was slightly different. Help in relapse prevention and seeking specialist aid was expressed by $57.14 \%$ of women. The willingness to look for the optimal method was expressed by $42.86 \%$ of the respondents.

\subsection{Quality of Life Assessment}

The analysis of the results of individual questionnaires, both in the study group and the control group, is presented in Table 3. The levels of depressive and anxiety disorders, amounting to $8.78 \pm 2.5$ (group B) and $11.48 \pm 3.0$ (group C), respectively, were higher in the study group compared to the control group $(p<00.1)$. The mean concerning particular sexual functions in comparison with the study group was demonstrated to be higher in the control group. The exception was the domain of pain during intercourse. The analysis of the results of the Mini-COPE questionnaire revealed that women with endometriosis less frequently demonstrated the strategy of active coping $(p=0.012)$, and positive reframing and development $(p<0.001)$. They showed a lower sense of humour $(p=0.002)$, a greater need to seek instrumental support $(p=0.049)$, and discontinued their actions more often $(p=0.005)$.

Table 3. Intergroup analysis of the results of the questionnaires: Mini-Cope, FSFI, HADS, and IPAQ.

\begin{tabular}{|c|c|c|c|c|c|c|c|c|c|c|}
\hline \multirow{2}{*}{\multicolumn{2}{|c|}{ Variable }} & \multicolumn{4}{|c|}{ Group B } & \multicolumn{4}{|c|}{ Group C } & \multirow{2}{*}{$p$-Value } \\
\hline & & $\mathbf{M}$ & Min & Max & SD & $\mathbf{M}$ & Min & Max & SD & \\
\hline \multirow{2}{*}{ HADS } & Depression & 8.78 & 2.00 & 18.00 & 2.50 & 5.08 & 0.00 & 18.00 & 3.15 & $<0.001$ * \\
\hline & Anxiety & 11.48 & 5.00 & 18.00 & 3.00 & 8.66 & 0.00 & 20.00 & 3.90 & $<0.001$ * \\
\hline \multirow{7}{*}{ FSFI } & Overall & 21.30 & 0.00 & 46.50 & 7.04 & 23.89 & 1.20 & 34.40 & 6.97 & $<0.001 *$ \\
\hline & Desire & 1.88 & 0.00 & 4.80 & 1.30 & 2.78 & 0.00 & 4.80 & 1.28 & $<0.001$ * \\
\hline & Excitement & 3.71 & 0.00 & 6.00 & 1.57 & 4.36 & 0.00 & 6.00 & 1.57 & $<0.001 *$ \\
\hline & Lubrication & 4.08 & 0.00 & 6.00 & 1.69 & 4.83 & 0.00 & 6.00 & 1.66 & $<0.001 *$ \\
\hline & Orgasm & 3.90 & 0.00 & 6.00 & 1.68 & 4.37 & 0.00 & 6.00 & 1.74 & $<0.001$ * \\
\hline & Satisfaction & 3.43 & 0.00 & 5.60 & 1.40 & 3.80 & 0.00 & 5.20 & 1.27 & $<0.001 *$ \\
\hline & Pain & 3.51 & 0.00 & 6.00 & 1.56 & 2.21 & 0.00 & 6.00 & 1.30 & $<0.001 *$ \\
\hline \multicolumn{2}{|r|}{ IPAQ } & 793.79 & 0.00 & \multicolumn{2}{|c|}{$10,956.001123 .05$} & 834.02 & 0.00 & \multicolumn{2}{|c|}{$14,680.001137 .22$} & 0.135 \\
\hline \multirow{14}{*}{$\begin{array}{l}\text { Mini- } \\
\text { COPE }\end{array}$} & Active coping & 1.89 & 0.00 & 3.00 & 0.83 & 2.05 & 0.00 & 3.00 & 0.74 & $0.012 *$ \\
\hline & Planning & 1.84 & 0.00 & 3.00 & 0.86 & 1.89 & 0.00 & 3.00 & 0.77 & 0.606 \\
\hline & Positive reframing and development & 1.33 & 0.00 & 3.00 & 0.87 & 1.58 & 0.00 & 3.00 & 0.78 & $<0.001 *$ \\
\hline & Acceptance & 1.59 & 0.00 & 3.00 & 0.82 & 1.70 & 0.00 & 3.00 & 0.75 & 0.069 \\
\hline & Turning to religion & 0.71 & 0.00 & 3.00 & 0.86 & 0.67 & 0.00 & 3.00 & 0.91 & 0.246 \\
\hline & Sense of humour & 0.67 & 0.00 & 3.00 & 0.62 & 0.81 & 0.00 & 3.00 & 0.66 & $0.002 *$ \\
\hline & Seeking emotional support & 1.62 & 0.00 & 3.00 & 0.90 & 1.67 & 0.00 & 3.00 & 0.93 & 0.424 \\
\hline & Self-distraction & 1.56 & 0.00 & 3.00 & 0.84 & 1.62 & 0.00 & 3.00 & 0.80 & 0.382 \\
\hline & Seeking instrumental support & 1.55 & 0.00 & 3.00 & 0.88 & 1.43 & 0.00 & 3.00 & 1.03 & $0.049 *$ \\
\hline & Denial & 0.75 & 0.00 & 3.00 & 0.76 & 0.75 & 0.00 & 3.00 & 0.76 & 0.970 \\
\hline & Venting & 1.42 & 0.00 & 3.00 & 0.71 & 1.49 & 0.00 & 3.00 & 0.73 & 0.216 \\
\hline & Use of alcohol and psychoactive substances & 0.36 & 0.00 & 3.00 & 0.66 & 0.45 & 0.00 & 3.00 & 0.76 & 0.293 \\
\hline & Discontinuation of actions & 0.79 & 0.00 & 3.00 & 0.71 & 0.67 & 0.00 & 3.00 & 0.70 & $0.005 *$ \\
\hline & Self-blame & 1.33 & 0.00 & 3.00 & 0.87 & 1.38 & 0.00 & 3.00 & 0.93 & 0.541 \\
\hline
\end{tabular}

Group B-study group; Group C—control group; M-arithmetic mean; SD—standard deviation; Min—minimum; Max—maximum; $p$-value-statistical significance; *-statistically significant value 
In the Table 4, the correlations of the HADS and IPAQ questionnaires with other variables used in the study were assessed. In group B, there was a correlation between the occurrence of depressive disorders and sexual functioning of women in the overall score $(p=0.021)$, in addition to the specific domains (desire, excitement, satisfaction) and in the strategy to deal with stress $(p=0.003)$. In group $C$, there was a correlation between depressive disorders and sexual functioning in the overall score $(p<0.001)$, and in all domains, except for pain during intercourse, and the level of physical activity $(p=0.002)$. The level of anxiety was negatively correlated with the FSFI $(p<0.001)$. The same influence of anxiety on women's sexual functioning was observed in group C $(p<0.001)$ as in group B. The observed changes concern both the total overall score of FSFI and all separate domains that were measured in the study. In the group of patients diagnosed with endometriosis, a relationship was found between the level of physical activity and the ability to cope with stress $(p=0.001)$.

Table 4. Correlations between the results of the questionnaires.

\begin{tabular}{|c|c|c|c|c|c|c|}
\hline & \multirow{2}{*}{\multicolumn{2}{|c|}{ Variable }} & \multicolumn{2}{|c|}{ Group B } & \multicolumn{2}{|c|}{ Group C } \\
\hline & & & $\mathbf{R}$ & $p$-Value & $\mathbf{R}$ & $p$-Value \\
\hline \multirow{16}{*}{ HADS } & \multirow{8}{*}{ Depression } & FSFI-overall & -0.10971 & $0.021 *$ & -0.31206 & $<0.001$ * \\
\hline & & FSFI-desire & -0.1109 & $0.020 *$ & -0.3004 & $<0.001 *$ \\
\hline & & FSFI-excitement & -0.1203 & $0.012 *$ & -0.2310 & $<0.001 *$ \\
\hline & & FSFI-lubrication & -0.0381 & 0.427 & -0.2448 & $<0.001 *$ \\
\hline & & FSFI-orgasm & -0.0812 & 0.090 & -0.2529 & $<0.001 *$ \\
\hline & & FSFI-satisfaction & -0.1051 & $0.028 *$ & -0.2860 & $<0.001$ * \\
\hline & & FSFI-pain & 0.0552 & 0.250 & 0.0839 & 0.086 \\
\hline & & IPAQ & -0.01737 & 0.717 & -0.14881 & $0.002 *$ \\
\hline & \multirow{8}{*}{ Anxiety } & FSFI-overall & -0.18758 & $<0.001 *$ & -0.33007 & $<0.001$ * \\
\hline & & FSFI-desire & -0.1346 & $0.005^{*}$ & -0.2522 & $<0.001$ * \\
\hline & & FSFI-excitement & -0.1203 & $0.012 *$ & -0.2806 & $<0.001$ * \\
\hline & & FSFI-lubrication & -0.1586 & $0.001 *$ & -0.2408 & $<0.001$ * \\
\hline & & FSFI-orgasm & -0.1451 & $0.002 *$ & -0.2915 & $<0.001$ * \\
\hline & & FSFI-satisfaction & -0.2215 & $<0.001 *$ & -0.3041 & $<0.001$ * \\
\hline & & FSFI-pain & 0.2046 & $<0.001 *$ & 0.2542 & $<0.001$ * \\
\hline & & IPAQ & 0.07447 & 0.119 & -0.00489 & 0.920 \\
\hline \multirow{9}{*}{ IPAQ } & \multicolumn{2}{|c|}{ FSFI-overall } & -0.00926 & 0.847 & 0.02139 & 0.662 \\
\hline & \multicolumn{2}{|c|}{$\begin{array}{l}\text { FSFI-overall } \\
\text { FSFI-desire }\end{array}$} & 0.0572 & 0.233 & -0.0471 & 0.335 \\
\hline & \multicolumn{2}{|c|}{ FSFI-excitement } & -0.0497 & 0.300 & -0.0117 & 0.811 \\
\hline & \multicolumn{2}{|c|}{ FSFI-lubrication } & -0.0085 & 0.860 & -0.0061 & 0.901 \\
\hline & \multicolumn{2}{|c|}{ FSFI-orgasm } & -0.0585 & 0.222 & -0.0589 & 0.228 \\
\hline & \multicolumn{2}{|c|}{ FSFI-satisfaction } & -0.0034 & 0.944 & -0.0262 & 0.593 \\
\hline & \multicolumn{2}{|c|}{ FSFI-pain } & 0.0908 & 0.058 & -0.0065 & 0.894 \\
\hline & \multicolumn{2}{|c|}{ HADS depression } & -0.01737 & 0.717 & -0.14881 & $0.002 *$ \\
\hline & \multicolumn{2}{|c|}{ HADS anxiety } & 0.07447 & 0.119 & -0.00489 & 0.920 \\
\hline
\end{tabular}

Group B-study group; Group C—control group; $p$-value-statistical significance; R-correlation coefficient; *-statistically significant value

Table 5 demonstrates the relationship between the level of physical activity and sexual functioning, depression and anxiety disorders, and strategies for coping with stress, taking into account the division according to endometriosis staging. A relationship was found between the level of physical activity and anxiety disorders $(p=0.015)$ and strategies for coping with stress, such as distraction $(p=0.007)$, and consumption of alcohol and other drugs $(p=0.029)$, among patients with the second stage of the disease. In patients with stage III endometriosis, a relationship between physical activity and active coping $(p=0.035)$, planning $(p=0.003)$, acceptance $(p=0.037)$, and distraction $(p=0.026)$ was found. Among women diagnosed with stage IV endometriosis, an association was observed between planning $(p=0.049)$, distraction $(p=0.008)$, and denial $(p=0.002)$. 
Table 5. Relationship between the level of physical activity and sexual functioning, ability to cope with stress, and the degree of anxiety and mood disorders, taking into account the clinical stage.

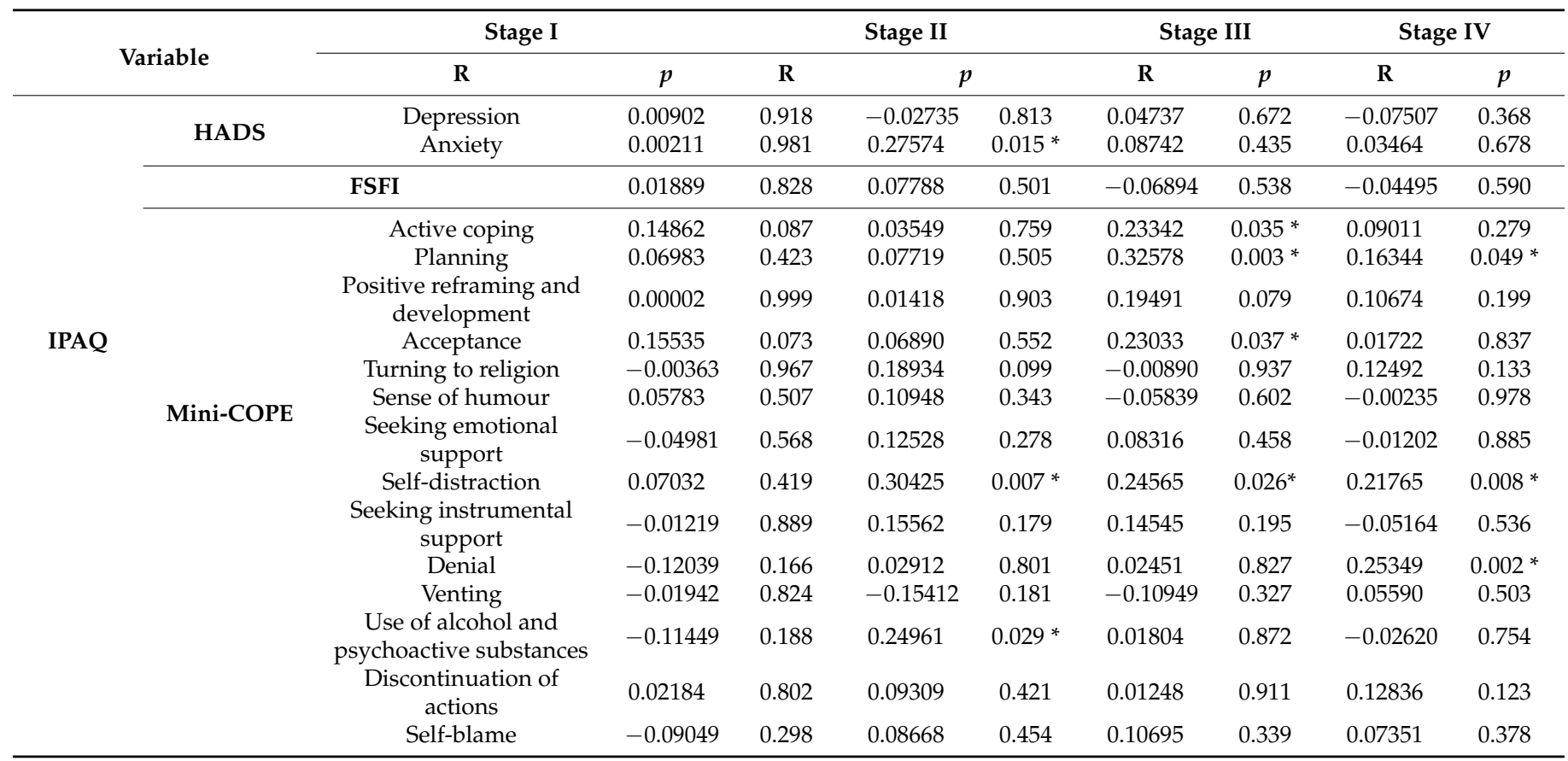

p-value-statistical significance; $\mathrm{R}$-correlation coefficient; * — statistically significant value

After the regression modelling was performed, adjusted for age, education, and cigarette smoking (Table 6$)$, a correlation between anxiety disorders $(p=0.014)$ and sexual functioning $(p=0.001)$, and the age of the patients was found. The level of education revealed a relationship between sexual functioning $(p=0.043)$ and the level of physical activity $(p=0.023)$.

Table 6. Multivariate logistic regression analysis.

\begin{tabular}{|c|c|c|c|c|c|c|c|c|c|c|c|c|}
\hline \multirow{3}{*}{$\begin{array}{c}\text { Variable } \\
\begin{array}{c}\text { HADS- } \\
\text { depression }\end{array}\end{array}$} & \multicolumn{4}{|c|}{ Age } & \multicolumn{4}{|c|}{ Education Level } & \multicolumn{4}{|c|}{ Cigarette Smoking } \\
\hline & \multirow{2}{*}{$\begin{array}{c}\beta \\
0.047954\end{array}$} & \multirow{2}{*}{$\begin{array}{c}\begin{array}{c}p- \\
\text { Value }\end{array} \\
0.358\end{array}$} & \multicolumn{2}{|c|}{$95 \%$ CI } & \multirow{2}{*}{$\begin{array}{c}\boldsymbol{\beta} \\
-0.08742\end{array}$} & \multirow{2}{*}{$\begin{array}{c}\begin{array}{c}p- \\
\text { Value }\end{array} \\
0.094\end{array}$} & \multicolumn{2}{|c|}{$95 \% \mathrm{CI}$} & \multirow{2}{*}{$\begin{array}{c}\boldsymbol{\beta} \\
0.040992\end{array}$} & \multirow{2}{*}{$\begin{array}{c}\begin{array}{c}p- \\
\text { Value }\end{array} \\
0.439\end{array}$} & \multicolumn{2}{|c|}{$95 \% \mathrm{CI}$} \\
\hline & & & -0.05451 & 0.150421 & & & -0.18985 & 0.015016 & & & -0.06304 & 0.145019 \\
\hline $\begin{array}{l}\text { HADS- } \\
\text { anxiety }\end{array}$ & -0.12881 & 0.014 * & -0.23178 & -0.02583 & -0.08084 & 0.123 & -0.18378 & 0.022105 & -0.05813 & 0.275 & -0.16267 & 0.046417 \\
\hline FSFI & -0.14992 & 0.001 * & -0.24384 & -0.05599 & -0.09718 & 0.043 * & -0.19108 & -0.00329 & -0.02813 & 0.562 & -0.12348 & 0.067228 \\
\hline IPAQ & 0.074198 & 0.117 & -0.01853 & 0.166922 & -0.1074 & $0.023 *$ & -0.20009 & -0.01471 & 0.063958 & 0.182 & -0.03018 & 0.158093 \\
\hline
\end{tabular}

Legend: $p$-value — statistical significance, $\mathrm{Cl}$-confidence interval, $\beta$ —standardized regression coefficient; ${ }^{*}$-statistically significant value.

\section{Discussion}

There are many studies in the available literature assessing the functioning of women diagnosed with endometriosis. This study is the first attempt at a multivariate analysis to assess the relationship between physical activity and individual variables, such as sexual function, anxiety, and depressive disorders, in addition to coping strategies, taking into account the stage of the disease.

Depression and anxiety are the most common disorders resulting from endometriosis [29-31,43-45]. In the present study, as in the study by Laganà et al. a higher level of depression and anxiety was found in women with endometriosis compared to healthy women [31]. Chen et al. confirmed the correlation between endometriosis and the presence of psychiatric disorders [30]. This study shows that there is no correlation between the 
symptoms of depression and anxiety and the stage of endometriosis. Other authors confirm this relationship [46-48]. A high level of psychopathological symptoms was more often diagnosed among women with pelvic pain [49-53]. Some authors have shown that pain may be the only cause of depression and anxiety among women with endometriosis [50,54]. However, the exact causality of this correlation could not be identified [46]. There are many confounding factors that may have influenced the obtained results. Age was an important aspect. Earlier studies have proven the influence of reduced oestrogen production in postmenopausal women on the relief of endometriosis symptoms [17]. Other variables are: duration of the disease, delay in diagnosis of endometriosis, social support, psychological aspects (e.g., stress, anxiety, depression, and family/work problems unrelated to the underlying disease), use of painkillers and opioids, infertility, pregnancy/successful delivery, response/non-response to treatment, patient's place of residence, financial status, access to health care, use of complementary or alternative forms of treatment, and predisposition to pain/chronic pain syndromes [55].

Pain during and after intercourse is a common problem that reduces the quality of sexual life among women with endometriosis [56-58]. According to Vercellini et al. women with endometriosis more often experienced dyspareunia [59]. The present study showed differences in sexual functioning between women with endometriosis and women without endometriosis. Similar results were presented in the work by Fairbanks et al. [60]. According to Ferrero et al. localisation of the disease within the cruciate ligaments was associated with greater discomfort during intercourse [61,62]. Sexual problems significantly affect the quality of a relationship [63,64]. Hämmerli et al. proved that sexual problems were more common among couples in which the woman had endometriosis [65]. Fritzer et al. showed statistically significant correlations between sexual dysfunction and a greater sense of guilt towards the partner, in addition to a decreased sense of femininity [66]. This relationship may have been the basis for the intensity of depression and anxiety in women with endometriosis that was noticed in the present study. Similar observations were demonstrated by Youseflu et al. who found a relationship between the occurrence of anxiety disorders, depression, and the level of sexual functioning [67]. Graaff et al. showed that depression was a significant negative predictor of sexual functioning [68].

Women with endometriosis have a greater tendency to show panic symptoms and an increased perception of stress [69]. No other studies were found to assess stress-coping strategies in women with endometriosis, and this study is the first to demonstrate such a relationship. According to the results, women with endometriosis needed more instrumental support. They rarely showed a strategy of active coping and more often discontinued their actions.

The decline in physical activity among women with endometriosis may be associated with pelvic pain [70]. According to the authors, physical exercise is an important factor in reducing pain [71,72]. Zhao et al. proved that progressive muscle relaxation training is effective in alleviating pain, anxiety, and depression in women with endometriosis undergoing hormone therapy [73]. Stanton et al. demonstrated a positive effect of physical activity on sexual function [74]. No studies have been found to assess the impact of physical activity on coping strategies. In the present study, the relationship between physical activity and individual aspects of women's quality of life was analysed for the first time, taking into account the clinical advancement of endometriosis.

\section{Limitations}

Due to the ongoing Sars-CoV-2 coronavirus pandemic, direct access to patients was difficult, and they were eventually brought together via appropriate online forums. As a result of the respondents filling in online questionnaires themselves, there is a risk of an information error. It was not possible to check and correct, if needed, the answers to individual questions. Another difficulty in conducting the study was obtaining answers to questions considering the intimate aspects of women's functioning. 


\section{Conclusions}

The occurrence of endometriosis affects the functioning of women in multiple aspects of life. The sexual function of women with endometriosis may be affected by the presence of mental disorders. Physical activity may be a factor that modifies the strategies of coping with stress among women with particular clinical stages of endometriosis.

Author Contributions: Conceptualization, A.M., A.T.-S., I.R. and A.C.-P.; methodology, A.M., A.T.S. and A.R.; software, P.B. and Z.H.; validation, A.M., A.T.-S. and A.R.; formal analysis, A.R.; investigation, A.M., P.B. and Z.H.; resources, A.M., K.M. and P.Ł.; data curation, A.M., A.T.-S., P.B., P.Ł. and Z.H.; writing—original draft preparation, A.M., P.B. and K.M.; writing-review and editing, A.T.-S., A.R., I.R. and A.C.-P.; visualization, A.M. and A.T.-S.; supervision, A.T.-S., A.R., I.R. and A.C.-P.; project administration, A.T.-S. and A.R.; funding acquisition, I.R. and A.C.-P. All authors have read and agreed to the published version of the manuscript.

Funding: This research received no external funding and the APC was funded by Pomeranian Medical University in Szczecin (WNoZ-321-01/S/2021).

Institutional Review Board Statement: The study was conducted according to the guidelines of the Declaration of Helsinki, and approved by the Bioethics Committee of the Pomeranian Medical University (protocol code KB-0012/47/04/2021/Z of 9 April 2021).

Informed Consent Statement: Informed consent was obtained from all subjects involved in the study.

Data Availability Statement: All data was collected in the Department of Medical Rehabilitation and Clinical Rehabilitation, Pomeranian Medical University, 71-210 Szczecin.

Conflicts of Interest: The authors declare no conflict of interest. The funders had no role in the design of the study; in the collection, analyses, or interpretation of data; in the writing of the manuscript, or in the decision to publish the results.

\section{References}

1. Bulun, S.E.; Yilmaz, B.D.; Sison, C.; Miyazaki, K.; Bernardi, L.; Liu, S.; Kohlmeier, A.; Yin, P.; Milad, M.; Wei, J. Endometriosis. Endocr. Rev. 2019, 1, 1048-1079. [CrossRef]

2. Scutiero, G.; Iannone, P.; Bernardi, G.; Bonaccorsi, G.; Spadaro, S.; Volta, C.A.; Greco, P.; Nappi, L. Oxidative Stress and Endometriosis: A Systematic Review of the Literature. Oxid. Med. Cell. Longev. 2017, 7265238. [CrossRef] [PubMed]

3. Soliman, A.M.; Yang, H.; Du, E.X.; Kelley, C.; Winkel, C. The direct and indirect costs associated with endometriosis: A systematic literature review. Hum. Reprod. 2016, 31, 712-722. [CrossRef] [PubMed]

4. Culley, L.; Law, C.; Hudson, N.; Denny, E.; Mitchell, H.; Baumgarten, M.; Raine-Fenning, N. The social and psychological impact of endometriosis on women's lives: A critical narrative review. Hum. Reprod. Update 2013, 19, 625-639. [CrossRef]

5. Wyderka, M.I.; Zalewska, D.; Szelag, E. Endometriosis and the quality of life. Piel. Pol. 2011, 4, $199-206$.

6. Macer, M.L.; Taylor, H.S. Endometriosis and infertility: A review of the pathogenesis and treatment of endometriosis-associated infertility. Obstet. Gynecol. Clin. N. Am. 2012, 39, 535-549. [CrossRef] [PubMed]

7. Bonocher, C.M.; Montenegro, M.L.; Rosa, E.; Silva, J.C.; Ferriani, R.A.; Meola, J. Endometriosis and physical exercises: A systematic review. Reprod. Biol. Endocrinol. 2014, 6, 4. [CrossRef] [PubMed]

8. Burney, R.O.; Giudice, L.C. Pathogenesis and pathophysiology of endometriosis. Fertil. Steril. 2012, 98, 511-519. [CrossRef] [PubMed]

9. Della Corte, L.; Di Filippo, C.; Gabrielli, O.; Reppuccia, S.; La Rosa, V.L.; Ragusa, R.; Fichera, M.; Commodari, E.; Bifulco, G.; Giampaolino, P. The Burden of Endometriosis on Women's Lifespan: A Narrative Overview on Quality of Life and Psychosocial Wellbeing. Int. J. Environ. Res. Public Health. 2020, 29, 4683. [CrossRef]

10. Hemmert, R.; Schliep, K.C.; Willis, S.; Peterson, C.M.; Louis, G.B.; Allen-Brady, K.; Simonsen, S.E.; Stanford, J.B.; Byun, J.; Smith, K.R. Modifiable life style factors and risk for incident endometriosis. Paediatr. Perinat. Epidemiol. 2019, 33, 19-25. [CrossRef] [PubMed]

11. Missmer, S.A.; Hankinson, S.E.; Spiegelman, D.; Barbieri, R.L.; Marshall, L.M.; Hunter, D.J. Incidence of laparoscopically confirmed endometriosis by demographic, anthropomet-ric, and lifestyle factors. Am. J. Epidemiol. 2004, 15, 784-796. [CrossRef] [PubMed]

12. Sroślak, K.; Ziętalewicz, U.; Pyrcz, P. The impact of endometriosis and its treatment methods on the quality of life and sexual functioning of women-A review of the latest research. Przegl. Seks. 2017, 1, 17-24.

13. Gordts, S.; Koninckx, P.; Brosens, I. Pathogenesis of deep endometriosis. Fertil. Steril. 2017, 108, 872-885.e1. [CrossRef]

14. Audebert, A. Endométriose stade III et IV: Implications physiopathologiques, cliniques et thérapeutiques [Physiopathology, diagnosis and therapeutic management of stage III and IV endometriosis]. J. Gynecol. Obstet. Biol. Reprod. 2003, 32, 15-19. 
15. Smorgick, N.; As-Sanie, S.; Marsh, C.A.; Smith, Y.R.; Quint, E.H. Advanced stage endome-triosis in adolescents and young women. J. Pediatr. Adolesc. Gynecol. 2014, 27, 320-323. [CrossRef]

16. Nisolle, M.; Nervo, P. Endométriose stade I et II: Implications physiopathologiques, cliniques et thérapeutiques [Physiopathology and therapeutic management of stage I and II endometriosis]. J. Gynecol. Obstet. Biol. Reprod. 2003, 32, 11-14.

17. Cope, A.G.; VanBuren, W.M.; Sheedy, S.P. Endometriosis in the postmenopausal female: Clinical presentation, imaging features, and management. Abdom. Radiol. 2020, 45, 1790-1799. [CrossRef] [PubMed]

18. Mundo-López, A.; Ocón-Hernández, O.; San-Sebastián, A.P.; Galiano-Castillo, N.; Rodríguez-Pérez, O.; Arroyo-Luque, M.S.; Arroyo-Morales, M.; Cantarero-Villanueva, I.; Fernández-Lao, C.; Artacho-Cordón, F. Contribution of Chronic Fatigue to Psychosocial Status and Quality of Life in Spanish Women Diagnosed with Endometriosis. Int. J. Environ. Res. Public Health 2020, 28, 3831. [CrossRef] [PubMed]

19. Chapron, C.; Marcellin, L.; Borghese, B.; Santulli, P. Rethinking mechanisms, diagnosis and management of endometriosis. Nat. Rev. Endocrinol. 2019, 15, 666-682. [CrossRef] [PubMed]

20. Pessoa de Farias Rodrigues, M.; Lima Vilarino, F.; de Souza Barbeiro Munhoz, A.; da Silva Paiva, L.; de Alcantara Sousa, L.V.; Zaia, V.; Parente Barbosa, C. Clinical aspects and the quality of life among women with endometriosis and infertility: A cross-sectional study. BMC Womens Health 2020, 12, 124. [CrossRef]

21. La Rosa, V.L.; De Franciscis, P.; Barra, F.; Schiattarella, A.; Török, P.; Shah, M.; Karaman, E.; Marques Cerentini, T.; Di Guardo, F.; Gullo, G.; et al. Quality of life in women with endometriosis: A narrative overview. Minerva Med. 2020, 111, 68-78. [CrossRef]

22. Rush, G.; Misajon, R. Examining subjective wellbeing and health-related quality of life in women with endometriosis. Health Care Women Int. 2018, 39, 303-321. [CrossRef]

23. Huntington, A.; Gilmour, J.A. A life shaped by pain: Women and endometriosis. J. Clin. Nurs. 2005, 14, 1124-1132. [CrossRef]

24. Sachedina, A.; Todd, N. Dysmenorrhea, Endometriosis and Chronic Pelvic Pain in Adolescents. J. Clin. Res. Pediatr. Endocrinol. 2020, 6, 7-17. [CrossRef] [PubMed]

25. Joseph, S.; Mahale, S.D. Endometriosis Knowledgebase: A gene-based resource on endometriosis. Database 2019 , baz062. [CrossRef]

26. As-Sanie, S.; Black, R.; Giudice, L.C.; Gray Valbrun, T.; Gupta, J.; Jones, B.; Laufer, M.R.; Mil-spaw, A.T.; Missmer, S.A.; Norman, A.; et al. Assessing research gaps and unmet needs in endometriosis. Am. J. Obstet. Gynecol. 2019, 221, 86-94. [CrossRef] [PubMed]

27. Findeklee, S.; Radosa, J.C.; Hamza, A.; Haj Hamoud, B.; Iordache, I.; Sklavounos, P.; Takacs, Z.F.; Solomayer, E.F.; Radosa, M. Treatment algorithm for women with endometriosis in a certified Endometriosis Unit. Minerva Ginecol. 2020, 72, 43-49. [CrossRef]

28. Facchin, F.; Barbara, G.; Saita, E.; Mosconi, P.; Roberto, A.; Fedele, L.; Vercellini, P. Impact of endometriosis on quality of life and mental health: Pelvic pain makes the difference. J. Psychosom. Obstet. Gynaecol. 2015, 36, 135-141. [CrossRef] [PubMed]

29. Friedl, F.; Riedl, D.; Fessler, S.; Wildt, L.; Walter, M.; Richter, R.; Schüßler, G.; Böttcher, B. Impact of endometriosis on quality of life, anxiety, and depression: An Austrian perspective. Arch. Gynecol. Obstet. 2015, 292, 1393-1399. [CrossRef]

30. Chen, L.C.; Hsu, J.W.; Huang, K.L.; Bai, Y.M.; Su, T.P.; Li, C.T.; Yang, A.C.; Chang, W.H.; Chen, T.J.; Tsai, S.J.; et al. Risk of developing major depression and anxiety disorders among women with endometriosis: A longitudinal follow-up study. J. Affect. Disord. 2016, 190, 282-285. [CrossRef]

31. Laganà, A.S.; Condemi, I.; Retto, G.; Muscatello, M.R.; Bruno, A.; Zoccali, R.A.; Triolo, O.; Cedro, C. Analysis of psychopathological comorbidity behind the common symptoms and signs of endometriosis. Eur. J. Obstet. Gynecol. Reprod. Biol. 2015, 194, 30-33. [CrossRef] [PubMed]

32. Biernat, E.; Stupnicki, R.; Gajewski, A.K. International Physical Activity Questionnaire (IPAQ)—Polish version. Wych. Fiz. Sport 2007, 51, 47-54.

33. Biernat, E. International Physical Activity Questionnaire-Polish Long Version. Med. Sport. 2013, 1, 1-15.

34. Craig, C.L.; Marshall, A.L.; Sjöström, M.; Bauman, A.E.; Booth, M.L.; Ainsworth, B.E.; Pratt, M.; Ekelund, U.; Yngve, A.; Sallis, J.F.; et al. International physical activity question-naire: 12-country reliability and validity. Med. Sci. Sports Exerc. 2003, 35, $1381-1395$. [CrossRef]

35. Meriwether, R.A.; McMahon, P.M.; Islam, N.; Steinmann, W.C. Physical activity as-sessment: Validation of a clinical assessment tool. Am. J. Prev. Med. 2006, 31, 484-491. [CrossRef]

36. Neijenhuijs, K.I.; Hooghiemstra, N.; Holtmaat, K.; Aaronson, N.K.; Groenvold, M.; Holzner, B.; Terwee, C.B.; Cuijpers, P.; Verdonck-de Leeuw, I.M. The Female Sexual Function Index (FSFI)-A Systematic Review of Measurement Properties. J. Sex. Med. 2019, 16, 640-660. [CrossRef] [PubMed]

37. Wiegel, M.; Meston, C.; Rosen, R. The female sexual function index (FSFI): Cross-validation and development of clinical cutoff scores. J. Sex. Marital. Ther. 2005, 31, 1-20. [CrossRef]

38. Crisp, C.C.; Fellner, A.N.; Pauls, R.N. Validation of the Female Sexual Function Index (FSFI) for web-based administration. Int. Urogynecol. J. 2015, 26, 219-222. [CrossRef]

39. Olssøn, I.; Mykletun, A.; Dahl, A.A. The Hospital Anxiety and Depression Rating Scale: Across-sectional study of psychometrics and case finding abilities in general practice. BMC Psychiatry 2005, 14, 46. [CrossRef]

40. Krzemińska, S.A.; Magolan, J.; Borodzicz, A.; Arendarczyk, M. Selected emotional problems of caregivers of patients fed by gastrostomy in domestic environment. Piel. Zdr. Pub. 2017, 7, 117-123. [CrossRef] 
41. Mocny-Pachońska, K.; Trzcionka, A.; Doniec, R.J.; Sieciński, S.; Tanasiewicz, M. The Influence of Gender and Year of Study on Stress Levels and Coping Strategies among Polish Dental. Medicina 2020, 12, 531. [CrossRef]

42. Białek, K.; Sadowski, M. Level of stress and strategies used to cope with stress by physicians working in intensive care units. Anaesthesiol. Intensive Ther. 2019, 51, 361-369. [CrossRef] [PubMed]

43. Vitale, S.G.; La Rosa, V.L.; Rapisarda, A.M.; Laganà, A.S. Impact of endometriosis on quality of life and psychological well-being. J. Psychosom. Obstet. Gynaecol. 2016, 18, 1-3. [CrossRef]

44. Pope, C.J.; Sharma, V.; Sharma, S.; Mazmanian, D. A systematic review of the association between psychiatric disturbances and endometriosis. J. Obstet. Gynaecol. Can. 2015, 37, 1006-1015. [CrossRef]

45. Laganà, A.S.; La Rosa, V.; Petrosino, B.; Vitale, S.G. Comment on “Risk of developing major depression and anxiety disorders among women with endometriosis: A longitudinal follow-up study". J. Affect. Disord. 2017, 208, 672-673. [CrossRef]

46. Sepulcri Rde, P.; do Amaral, V.F. Depressive symptoms, anxiety, and quality of life in women with pelvic endometriosis. Eur. J. Obstet. Gynecol. Reprod. Biol. 2009, 142, 53-56. [CrossRef]

47. Hassa, H.; Tanir, H.M.; Uray, M. Symptom distribution among infertile and fertile endometriosis cases with different stages and localisations. Eur. J. Obstet. Gynecol. Reprod. Biol. 2005, 119, 82-86. [CrossRef]

48. Warzecha, D.; Szymusik, I.; Wielgos, M.; Pietrzak, B. The Impact of Endometriosis on the Quality of Life and the Incidence of Depression-A Cohort Study. Int. J. Environ. Res. Public Health 2020, 17, 3641. [CrossRef] [PubMed]

49. Eriksen, H.L.; Gunnersen, K.F.; Sørensen, J.A.; Munk, T.; Nielsen, T.; Knudsen, U.B. Psychological aspects of endometriosis: Differences between patients with or without pain on four psychological variables. Eur. J. Obstet. Gynecol. Reprod. Biol. 2008, 139, 100-105. [CrossRef]

50. Tripoli, T.M.; Sato, H.; Sartori, M.G.; de Araujo, F.F.; Girão, M.J.; Schor, E. Evaluation of quality of life and sexual satisfaction in women suffering from chronic pelvic pain with or without endometriosis. J. Sex. Med. 2011, 8, 497-503. [CrossRef]

51. Souza, C.A.; Oliveira, L.M.; Scheffel, C.; Genro, V.K.; Rosa, V.; Chaves, M.F.; Cunha Filho, J.S. Quality of life associated to chronic pelvic pain is independent of endometriosis diagnosis-A cross-sectional survey. Health Qual. Life Outcomes 2011, 9, 41. [CrossRef]

52. Kumar, A.; Gupta, V.; Maurya, A. Mental health and quality of life of chronic pelvic pain and endometriosis patients. J. Proj. Psychol. Ment. Health. 2010, 17, 153-157.

53. Lorençatto, C.; Petta, C.A.; Navarro, M.J.; Bahamondes, L.; Matos, A. Depression in women with endometriosis with and without chronic pelvic pain. Acta Obstet. Gynecol. Scand. 2006, 85, 88-92. [CrossRef]

54. Roth, R.S.; Punch, M.; Bachman, J.E. Psychological factors in chronic pelvic pain due to endometriosis: A comparative study. Gynecol. Obstet. Investig. 2011, 72, 15-19. [CrossRef]

55. Missmer, S.A.; Tu, F.F.; Agarwal, S.K.; Chapron, C.; Soliman, A.M.; Chiuve, S.; Eichner, S.; Flores-Caldera, I.; Horne, A.W.; Kimball, A.B.; et al. Impact of Endometriosis on Life-Course Potential: A Narrative Review. Int. J. Gen. Med. 2021, 14, 9-25. [CrossRef] [PubMed]

56. Yang, X.; Xu, X.; Lin, L.; Xu, K.; Xu, M.; Ye, J.; Shen, X. Sexual function in patients with endometriosis: A prospective case-control study in China. J. Int. Med. Res. 2021, 49, 3000605211004388. [CrossRef]

57. Grangier, L.; Aerts, L.; Pluchino, N. Les dyspareunies chez les patientes atteintes d'endométriose [Clinical investigation of Sexual pain in patients with endometriosis]. Rev. Med. Suisse 2019, 15, 1941-1944.

58. Youseflu, S.; Jahanian Sadatmahalleh, S.; Bahri Khomami, M.; Nasiri, M. Influential factors on sexual function in infertile women with endometriosis: A path analysis. BMC Womens Health 2020, 20, 92. [CrossRef]

59. Vercellini, P.; Viganò, P.; Somigliana, E.; Fedele, L. Endometriosis: Pathogenesis and treatment. Nat. Rev. Endocrinol. 2014, 10, 261-275.44. [CrossRef] [PubMed]

60. Fairbanks, F.; Abdo, C.H.; Baracat, E.C.; Podgaec, S. Endometriosis doubles the risk of sexual dysfunction: A cross-sectional study in a large amount of patients. Gynecol. Endocrinol. 2017, 33, 544-547. [CrossRef]

61. Ferrero, S.; Abbamonte, L.H.; Parisi, M.; Ragni, N.; Remorgida, V. Dyspareunia and quality of sex life after laparoscopic excision of endometriosis and postoperative administration of triptorelin. Fertil. Steril. 2007, 87, 227-229. [CrossRef]

62. Denny, E.; Mann, C.H. Endometriosis-associated dyspareunia: The impact on women's lives. J. Fam. Plann. Reprod. Health Care 2007, 33, 189-193. [CrossRef] [PubMed]

63. Aerts, L.; Grangier, L.; Streuli, I.; Dällenbach, P.; Marci, R.; Wenger, J.M.; Pluchino, N. Psychosocial impact of endometriosis: From co-morbidity to intervention. Best Pract. Res. Clin. Obstet. Gynaecol. 2018, 50, 2-10. [CrossRef]

64. Pluchino, N.; Wenger, J.M.; Petignat, P.; Tal, R.; Bolmont, M.; Taylor, H.S.; Bianchi-Demicheli, F. Sexual function in endometriosis patients and their partners: Effect of the disease and consequences of treatment. Hum. Reprod. Update 2016, 22, 762-774. [CrossRef] [PubMed]

65. Hämmerli, S.; Kohl-Schwartz, A.; Imesch, P.; Rauchfuss, M.; Wölfler, M.M.; Häberlin, F.; von Orelli, S.; Leeners, B. Sexual Satisfaction and Frequency of Orgasm in Women with Chronic Pelvic Pain due to Endometriosis. J. Sex. Med. 2020, 17, 2417-2426.50. [CrossRef]

66. Fritzer, N.; Haas, D.; Oppelt, P.; Renner, S.; Hornung, D.; Wölfler, M.; Ulrich, U.; Fischerlehner, G.; Sillem, M.; Hudelist, G. More than just bad sex: Sexual dysfunction and distress in patients with endometriosis. Eur. J. Obstet. Gynecol. Reprod. Biol. 2013, 169, 392-396. [CrossRef] [PubMed]

67. Youseflu, S.; Jahanian Sadatmahalleh, S.; Roshanzadeh, G.; Mottaghi, A.; Kazemnejad, A.; Moini, A. Effects of endometriosis on sleep quality of women: Does life style factor make a difference? BMC Womens Health 2020, 10, 168. [CrossRef] 
68. De Graaff, A.A.; Van Lankveld, J.; Smits, L.J.; Van Beek, J.J.; Dunselman, G.A. Dyspareunia and depressive symptoms are associated with impaired sexual functioning in women with endometriosis, whereas sexual functioning in their male partners is not affected. Hum. Reprod. 2016, 31, 2577-2586. [CrossRef]

69. Donatti, L.; Ramos, D.G.; Andres, M.P.; Passman, L.J.; Podgaec, S. Patients with endometriosis using positive coping strategies have less depression, stress and pelvic pain. Einstein 2017, 15, 65-70. [CrossRef]

70. Awad, E.; Ahmed, H.A.H.; Yousef, A.; Abbas, R. Efficacy of exercise on pelvic pain and posture associated with endometriosis: Within subject design. J. Phys. Ther. Sci. 2017, 29, 2112-2115. [CrossRef]

71. Leonardi, M.; Horne, A.W.; Vincent, K.; Sinclair, J.; Sherman, K.A.; Ciccia, D.; Condous, G.; Johnson, N.P.; Armour, M. Selfmanagement strategies to consider to combat endometriosis symptoms during the COVID-19 pandemic. Hum. Reprod. Open. 2020, 1, hoaa028. [CrossRef] [PubMed]

72. Bergström, I.; Freyschuss, B.; Jacobsson, H.; Landgren, B.M. The effect of physical training on bone mineral density in women with endometriosis treated with GnRH analogs: A pilot study. Acta Obstet. Gynecol. Scand. 2005, 84, 380-383. [CrossRef] [PubMed]

73. Zhao, L.; Wu, H.; Zhou, X.; Wang, Q.; Zhu, W.; Chen, J. Effects of progressive muscular relaxation training on anxiety, depression and quality of life of endometriosis patients under gonadotrophin-releasing hormone agonist therapy. Eur. J. Obstet. Gynecol. Reprod. Biol. 2012, 162, 211-215. [CrossRef]

74. Stanton, A.M.; Handy, A.B.; Meston, C.M. The Effects of Exercise on Sexual Function in Women. Sex. Med. Rev. 2018, 6, 548-557. [CrossRef] [PubMed] 